\title{
11. Theory: An informatics perspective
}

\author{
Craig McDonald \\ University of Canberra
}

\section{Abstract}

This chapter explores the concept of theory from an informatics perspective. That is, it frames a theory as a conceptual pattern, an information construct or ontology, and theory building as a process that creates uses and modifies a pattern. An agenda for information systems as a discipline for explicit pattern management is proposed.

\section{Introduction}

Suppose you are driving your car out in the country on a fine day. You are listening to a radio play on the stereo, watching the road, enjoying the view and the whole motoring experience. A police car appears out of nowhere and invites you to pull over. You do so, get out of your car and talk with the policeman. He says you were driving over the speed limit, that the speed limit on that stretch of road is $100 \mathrm{~km} / \mathrm{h}$ and you were driving at $111 \mathrm{~km} / \mathrm{h}$ according to his radar. In accordance with the Motor Traffic Act, the policeman says, he will issue you with a speeding fine. You object, saying that you were not travelling at the claimed speed. You ask your car computer to print out your data for the past 10 minutes, which it does, and the printout shows that $105 \mathrm{~km} / \mathrm{h}$ was your fastest speed in that time.

There are many ways of framing this simple scenario. A sociologist might frame the scenario in terms of the power relations between driver and policeman; a psychologist might frame it in terms of mental states and disposition; a technologist might focus on the differences between the speed-recording devices; a police commander in terms of the fine income, and so on. The frame one selects will determine the kinds of concepts and relationships between concepts that are brought to bear on and extracted from the scenario. In what follows, we ask how this scenario could be seen in an informatics frame and derive, from what we find, some implications for theory and theory building in the information systems (IS) discipline. 


\section{A 'Grand Theory'}

We can interpret the simple tale of the previous section using an old 'grand theory' that captures the essence of the informatics concept. This theory argues that there are three different kinds of things in the universe; that there are three different 'worlds', as Popper (1972) calls them. Things of the first kind are physical objects (roads, cars, speed-limit signs, and so on), apparent forces (gravity, wind, and so on) and their interactions. The disciplines that study this physical 'world one' include physics, chemistry, ecology, astronomy, and so on. Things of the second kind are cognitive processes - thinking, consciousness and creativity in the mind (including intelligence of many forms, both natural and artificial) - that are studied by psychology, artificial intelligence, linguistics, education, and so on. Third comes the semantic world of information comprising data, statements and articulated knowledge that are carried in language and that are studied by the informatics disciplines including information science, information systems, statistics, library studies, mathematics, communication, journalism, and so on. One form of interdisciplinarity involves studying the interactions between the worlds and this includes such disciplines as communications, social sciences, economics, and so on.

These three worlds interact: minds perceive the physical world, they interpret what they perceive in terms of their beliefs, values and their understanding of the social situation, they express their thoughts in statements and in bodily actions. In our scenario there are two minds: yours and the policeman's; both have perceptions of your car's speed, the speed limit at the relevant place, and both have understandings of the Motor Traffic Act (the road rules) although these perceptions and understandings might be quite different. You communicate through statements in a common language but nevertheless probably use that language sufficiently differently so that communication is less than perfect. Your car's computer and the policeman's radar have artificial intelligencethat is, they have 'perceptions' of the physical world and they 'express' their 'understanding' in 'language'. For a longer discussion of the three-worlds idea, see McDonald (2002).

Figure 11.1 shows a diagram of the scenario seen through the three-worlds conceptual lens.

This way of seeing the universe, this old 'grand theory', is not new; versions of it date back at least to Plato's cave allegory and to Aristotle. The elaboration by Karl Popper is, though, perhaps the best known of the more recent versions. In Popper's view, reality is divided into three parts: 'first, the world of physical objects or of physical states; secondly the world of states of consciousness, or of mental states, or perhaps of behavioural dispositions to act; and thirdly, the world of objective contents of thought' (Popper, 1972, p. 106). 
Popper distinguished thought, in the sense of the content of statements, and thought, in the sense of thought processes, as belonging to two entirely different worlds. "If we call the world of "things" — of physical objects - the first world, and the world of subjective experiences (such as thought processes) the second world, we may call the world of statements in themselves the third world' (Popper, 1976, pp. 180-1).

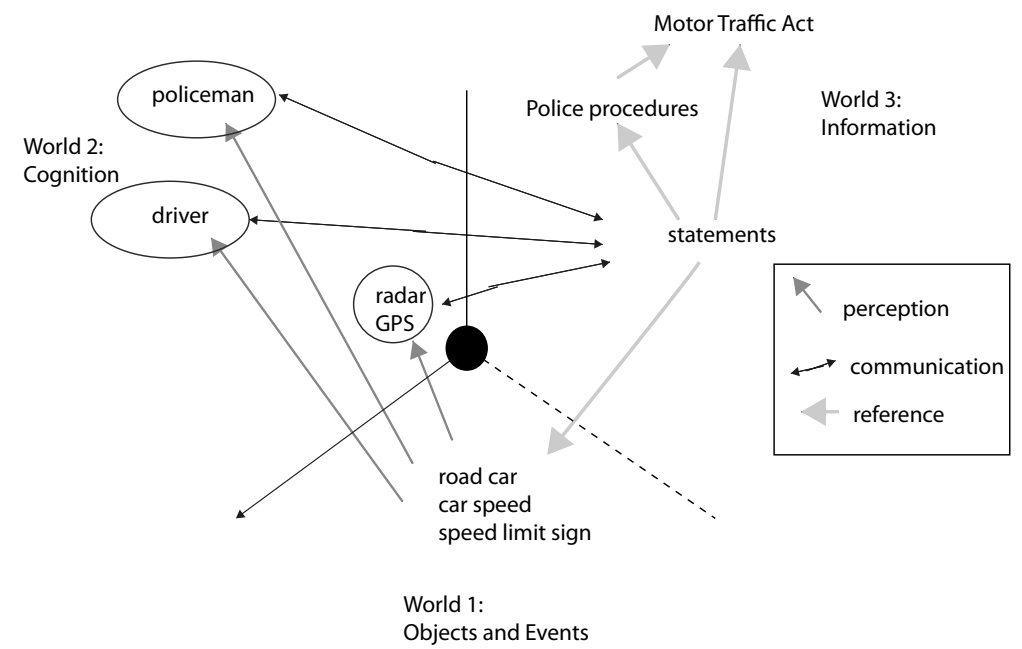

Figure 11.1 Popper's Three-World Model Illustrated Using the 'Speeding' Scenario

The 'grand theory' accommodates other ways of understanding informatics as, for example, the 'meaning triangle' (Odgen and Richards, 1923) shown in Figure 11.2. Similarly, Figure 11.3 shows how semiotics (after Peirce) and the threeworlds view fit together. There are also many other philosophies that rest on a three-part view of the world: the physical, the mental and the abstract.

The scenario described at the start of this chapter involved two minds, both formed through quite different generic and experiential histories and so seeing the world quite differently when the scenario begins. If the 'information' each received was the same, they would interpret it differently, but of course the 'information' each receives is not the same. So the interaction between these two minds is partly about vehicle speed in world one, partly about their own worldtwo states, and partly about the Motor Traffic Act in world three.

Of course a mind perceives and interprets masses of signals. A grand theory, alternative to this one, might start from the mind and conceive of 'information' as being anything that informs the mind ('environmental information', as Floridi, 2010, would have it). The purpose of the grand theory in this chapter, however, is to provide an account of the world for IS use, not for a study of mind. 


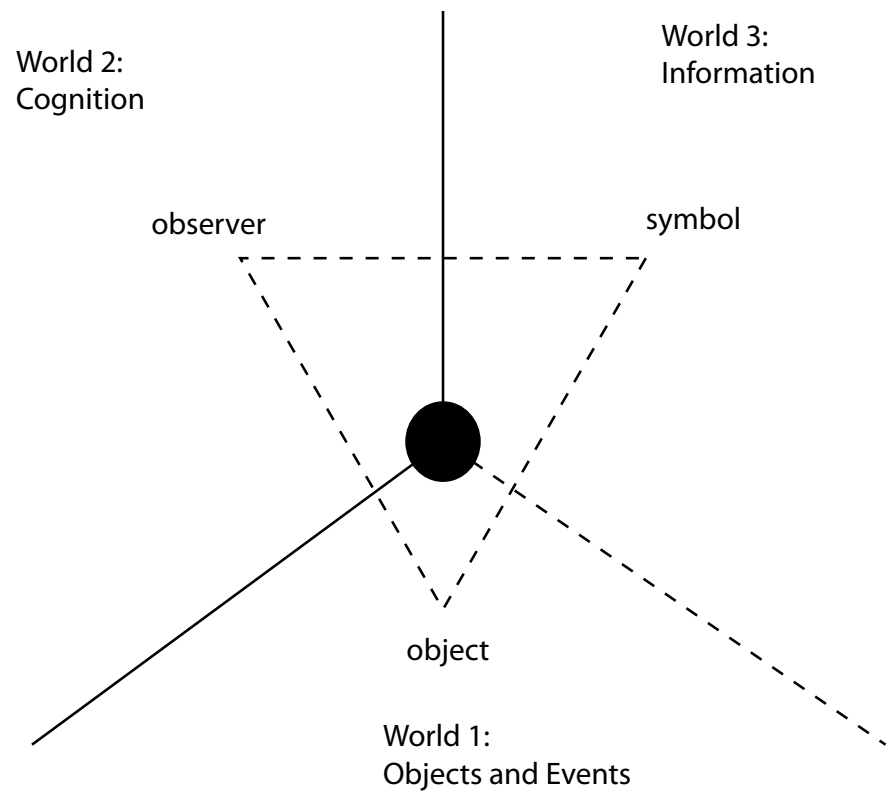

Figure 11.2 The Meaning Triangle

World 2:

Cognition
World 3:

Information

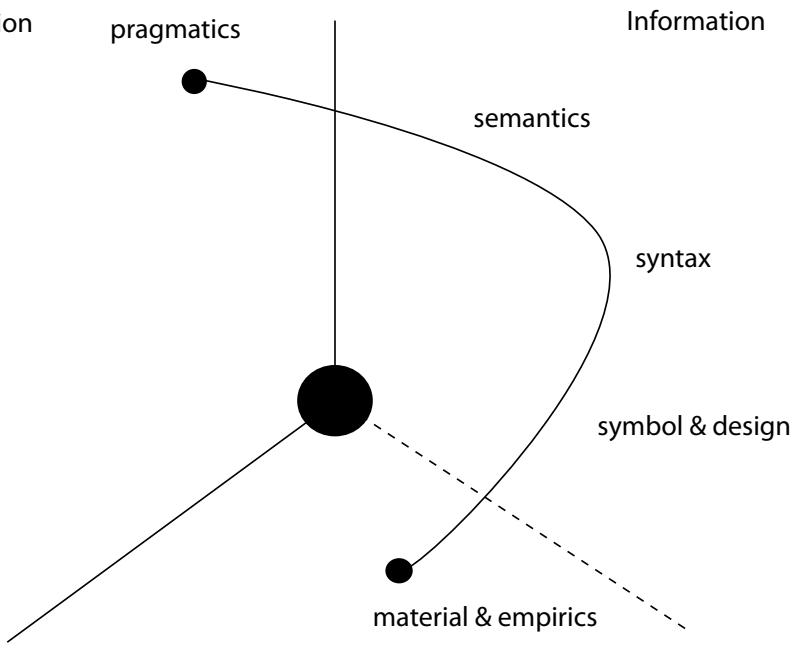

World 1:

Objects and Events

Figure 11.3 Semiotics and Popper's Three Worlds 
One way to unpack world three, from an IS perspective, is to consider the different forms that information can take. The history of modern IS is, arguably, grounded in the development of electronic data-processing (EDP) systems and built on subsequent computing technologies. Electronic data-processing systems recognise two forms of information. The first is data that take the form of a statement asserting the value of an attribute of an object at a point in time. An example would be the temperature (attribute) of this room (object) being 21 degrees (value). The second form information can take is process knowledge describing how data can be processed. This articulated knowledge may be in the form of processes and procedures or coded into computer executable algorithms, scripts, and so on. The role of IS was to design systems that:

- represented an understanding of an information domain in terms of data and the knowledge of how to process them

- executed that understanding by capturing data and processing them effectively for human use.

Such systems are tightly governed by an ontology, represented in meta-data and rule specifications. While ontology-governed systems remain the backbone of the IS professional focus, communications systems dealing with other forms of digital objects usually operate in parallel. Communication systems, including email, social media, and so on, accept, transmit and display content that is not rigorously governed. From a technology perspective, the acronym ICT (information and communication technologies) is an indicator of separation between systems of information and those of communication.

\section{Some Anomalies in the 'Grand Theory'}

'Grand theories' are useful in all disciplines to contextualise and bring together more empirical theory work in the domain. They give a sense of wholeness to a body of work and provide the large ontological categories that allow researchers to better ground their work or at least to challenge more orthodox views. There is a tendency in the informatics disciplines, especially when humanities and social sciences approaches are brought in, to invent jargon and reuse concepts so as to make a 'new' research field incommensurable with the existing work. While this tendency might resonate with some universities, funding bodies and conferences, it fragments the serious descriptive, explanatory, predictive and design powers of the discipline.

All theory is tentative and subject to test and challenge. The grand theory is no exception. It might need some revision in the light of technical change as well as other inherent theoretical issues. 
Some technology changes were indicated above in the discussion of information forms, and new phenomena that appear need to be analysed to see how they fit with existing high-level understandings. With this in mind, note that worldthree statements are concepts and relationships, so images and signal datasets do not qualify as citizens of world three. They remain world-one entities until they are processed and some information is drawn from them and posted into world three.

World three is a very literal place. It comprises statements - where a statement is a structure of concepts or categories whose instances are referred to. Data statements have a single instance, knowledge statements refer to instances of a particular kind and text statements are rather a mixed bag. As these statements exist independently of their author, they are open to examination and test to determine their veracity; their truth or falsehood. But it is not always easy to tell whether statements are literal or not. Much human communication in language is metaphoric, poetic or intentionally misleading. For example, Frankfurt (2005) gives a description of insidious non-literal statements:

It is impossible for someone to lie unless he thinks he knows the truth.

Producing bullshit requires no such conviction.

A person who lies is thereby responding to the truth, and he is to that extent respectful of it.

When an honest man speaks, he says only what he believes to be true; and for the liar, it is correspondingly indispensable that he considers his statements to be false.

For the bullshitter, however, all these bets are off: he is neither on the side of the true nor on the side of the false.

His eye is not on the facts at all, as the eyes of the honest man and of the liar are, except insofar as they may be pertinent to his interest in getting away with what he says.

He does not care whether the things he says describe reality correctly.

He just picks them out, or makes them up, to suit his purpose. (Paraphrased from pp. 55-6)

Margaret Thatcher (1987) famously said '[t]here is no such thing as society'. This is puzzling. In the grand theory, information is statements that refer to something, so there needs to be 'society' for the statement to be literal, but if there is 'society' then the statement cannot be true. Perhaps this is one for the new subcategory 'statements not to be taken literally'. But it raises the question of what kind of concept is 'society'? 
A similar question arises from the scenario at the start of this chapter. The Motor Traffic Act is a law that governs the behaviour of police and drivers alike. It is a set of statements, but has a very different role in world three than do data or text statements. It is a referent in its own right. Ontologies, vocabularies and theories are also concepts that have been mentioned in this chapter and they are all alike in being referred to by statements, but which do not do any referring themselves. They are instead long-term, stable patterns that govern discourse and behaviour and that have strong social systems that support and enforce them.

\section{A 'Grand Theory' Modification}

An important new part of world three needs to be created: patterns. Figure 11.4 shows the place of the pattern part of world three with some examples of significant types of patterns. The figure also gives an indication of their degree of specification formality and the degree of social deliberation that goes into their creation and maintenance.

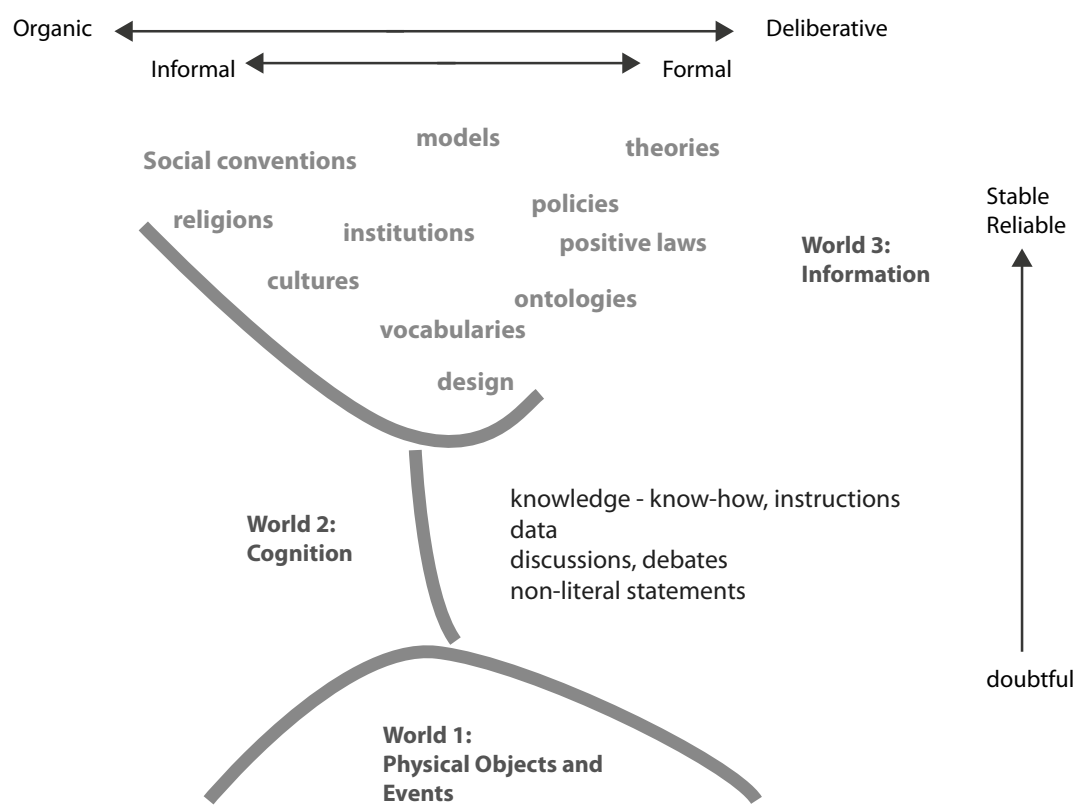

\section{Figure 11.4 The Place of Patterns in World Three}

The identification of a pattern subclass in the information world better accounts for the phenomena identified above as problematic. It is a place for articulated conceptual structures, for the big ideas that lurk in the background of our everyday lives. The grand theory does not suggest that patterns are based 
in physical reality; some of the most powerful patterns have little to do with the physical world. There are big questions about the conceptual structure of English society, but Thatcher was wrong to say that it does not exist since it is a pattern.

Social processes create and modify patterns that give them their 'warrant' with a population. Patterns are rarely the product of one mind.

Patterns are internalised in each world-two mind more or less faithfully through its experience, acculturation and education. Each mind has its own knowledge, and that knowledge changes over time. One's internalised patterns underlie perceptions and actions. External patterns are a touchstone for reflecting on why one thinks and acts the way one does.

Patterns provide the referent necessary to test statements, expose bullshit, and so on. Attempts to more formally articulate informal patterns might reveal just how little we really know about the non-physical world humanity has built.

\section{Theory and Theory Building}

Theory can be seen as an articulated pattern of concepts and relationships that has gained stable, reliable status in academic disciplines through a process of research, debate and publication and which functions to describe, explain and predict phenomena (Gregor, 2002). The conceptual graphs formalism of Sowa $(1984,2000)$ provides a means to represent precisely the components and structure of a theory. If a theory cannot be represented this way, perhaps it still contains connotation rather than being denotative.

In his discussion of theory and theory building, Weber (2003) concentrates on the constructs, laws, states and events that make up theory. Like so much theoretical writing, the position is sound, but fails to recognise its own theoretical context. It does not recognise any larger theoretical space of which it is a part, or in what way it is a part of that space. It does not recognise its similar but different siblings.

Much IS research is characterised by weak articulation of its theoretical context, so the discipline appears fragmented and has had difficulty building coherent, stable theory. The Theories Used in IS Research Wiki (BYU, 2011), for example, is a useful catalogue but it is an unstructured collection. The hard conceptual work of theorising about this collection of theories at the next level of abstraction seems still to be done.

Literature views in IS theory building are supposed to provide a conceptual framework for a research project. Unfortunately, they often seem to simply 
identify other work in the field of interest instead of producing a conceptual framework that locates the field upwards into a general theoretical context and sideways to distinguish it from adjacent or overlapping work. Typically, all that is done is to propose a concept and work downwards to operationalise variables for analysis. Information systems journal editors, research supervisors, examiners, reviewers and research educators would do well to heed Christopher Alexander's words:

[W] hen you build a thing you cannot merely build that thing in isolation, but must also repair the world around it, and within it, so that the larger world at that one place becomes more coherent, and more whole; and the thing which you make takes its place in the web of nature, as you make it. (Alexander et al., 1977, p. xiii)

\section{Conclusion}

Perhaps one of the most longstanding interests of the informatics disciplines (those that study information) has been the representation of our understanding of the world and the construction of human and technical systems that deploy that understanding.

Grand theory is important for two reasons. First, it puts the informatics disciplines in context and is itself a pattern against which disciplinary debate can be conducted. Second, because patterns are an information construct, they are susceptible to examination and systems building by the IS discipline.

There is vast scope for IS research to be done on the specification of different pattern types, technology for representation and deployment, systems for theory building, quality of representation and lines of evidence, data curation and reuse, and industry deployment through instruments and designs. Information systems should be defining the human and systems aspects of the development and maintenance of the pattern part of world three.

Ontological technologies for industry, semantic web development and e-research are all developing technologically without the systems context that IS should bring to them. Information domains including legal informatics, health informatics and government informatics are all adopting ontologies without the systems aspects that IS should bring to them. Yet IS does not seem to see these trends or its place in them.

This chapter has suggested a modification to a grand theory of informatics to accommodate patterns of various kinds to better account for information 
phenomena. It has argued for IS theory and theory building to become more coherent and theoretically integrated using patterns and for IS to take on pattern explication as an area of research and development.

\section{References}

Alexander, C., Ishikawa, S., Silverstein, M., Jacobson, M., Fiksdahl-King, I., \& Angel, S. (1977). A Pattern Language: Towns, buildings, construction. Oxford, UK: Oxford University Press.

BYU (2011). Theories Used in IS Research Wiki, < http://istheory.byu.edu/wiki/ Main_Page>

Floridi, L. (2010). Information: A very short introduction. Oxford, UK: Oxford University Press.

Frankfurt, H. G. (2005). On Bullshit. Princeton, NJ: Princeton University Press.

Gregor, S. (2002). A theory of theories in information systems. In S. Gregor \& D. Hart (eds), Information Systems Foundations: Building the theoretical base (pp. 1-10). Canberra, ACT: ANU E Press.

McDonald, C. (2002). Information systems foundations-Karl Popper's third world. Australasian Journal of Information Systems, 10(1), 59-69.

Odgen, C. K., \& Richards, I. A. (1923). The Meaning of Meaning. New York, NY: Harcourt Brace.

Popper, K. R. (1972). Objective Knowledge, An Evolutionary Approach. Oxford, UK: Clarendon Press.

Popper, K. R. (1976). Unended Quest: An intellectual autobiography. New York, NY: Fontana.

Sowa, J. F. (1984). Conceptual Structures: Information processing in mind and machine. Boston, Mass.: Addison-Wesley.

Sowa, J. F. (2000). Knowledge Representation: Logical, philosophical and computational foundations. Pacific Grove: Calif.: Brooks/Cole.

Thatcher, M. (1987). <http://www.margaretthatcher.org/document/106689>

Weber, R. (2003). Theoretically speaking. MIS Quarterly, 27(3), iii-xii. 